\title{
A refresher on rubella
}

Background and epidemiology: In March 2005 the US Centers for Disease Control and Prevention posted an early-release article online that announced the elimination of endemic rubella and congenital rubella syndrome (CRS) in the United States. ${ }^{1}$ The statement was based on the low number of reported rubella cases in that country (<25 since 2001), the high vaccination coverage rate among school-aged children (>95\%), the high estimated population immunity (91\%), the adequate surveillance system in place to detect rubella outbreaks and the pattern of virus genotypes consistent with virus origination in other parts of the world. ${ }^{1}$ The indigenous circulation of rubella in the United States has been interrupted thanks mostly to an $\ddot{*}$ established and effective vaccination program.

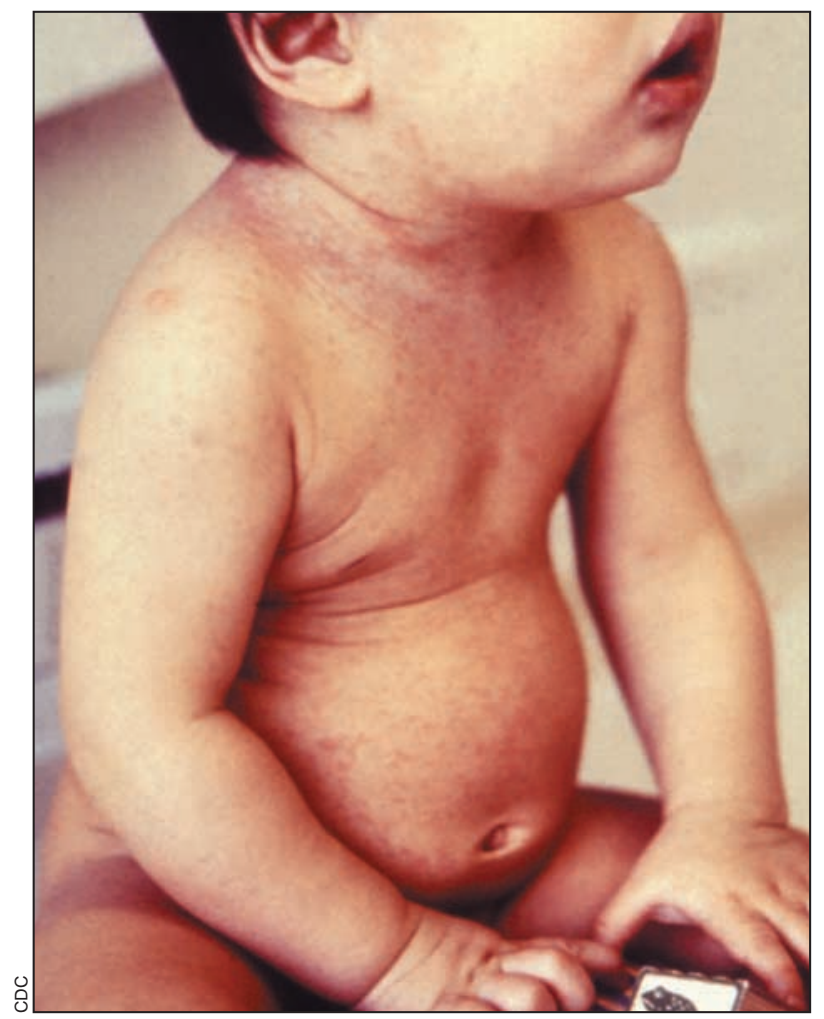

Infant with mild rubella rash. Although generally a mild illness, rubella is associated with a high risk of fetal wastage or birth defects (congenital rubella syndrome) if contracted in the early months of gestation.
Canada for the most part shares in this achievement. Since Canada introduced rubella vaccination in 1969 , the incidence of the disease has fallen dramatically, with an average of 1000 cases occurring each year between 1986 and 1995 and the number dwindling to only 29 cases in 2000. Unfortunately 2005 is proving to be an atypical year, with more than 220 confirmed rubella cases spanning 3 counties in Ontario. Most of the cases have involved members of a religious community in which many members have not been vaccinated or have not accepted the full range of vaccines routinely recommended. As public health officials work to contain the outbreak and advise about the risks, the potential for broader spread of rubella warrants review of key clinical features of the disease and preventive strategies, especially as they relate to identifying and addressing susceptible patients in primary care and specialty practices.

The rubella virus is a member of the Togaviridae family. Infection is acquired through contact or droplet transmission. The virus infects cells in the upper respiratory tract and replicates in the lymphoid system, after which a viremia leads to systemic infection involving many organs. In pregnant women, this includes the placenta, which puts the fetus at high risk of CRS. Transmission from infected people can occur up to 7 days before and 7 days after the onset of symptoms, especially rash. Up to $50 \%$ of cases are asymptomatic yet infectious, which is why an important compoennt of managing a rubella outbreak involves identifying the epidemiologic links between potentially infected and exposed individuals.

In general, rubella is a mild illness. In children, constitutional features are mild or absent before the development of a transient rash, typically appearing 7-10 days after infection. Infected adults tend to experience more constitutional symptoms, and postpubertal women in particular are susceptible to lingering arthralgia. The most vulnerable, however, are fetuses, who are at high risk of CRS, particularly if exposed to the virus during the first 10 weeks of pregnancy. [Clinical features of CRS are listed in Box 1 of the article on page 1678 of this issue - Ed.]

Clinical management: Clinical diagnosis of rubella is unreliable. Laboratory confirmation to investigate $\operatorname{IgG}$ and $\operatorname{IgM}$ titres is essential for definitive diagnosis. In North America the differential diagnosis includes infection with human parvovirus B19, herpes virus 6, measles, West Nile virus and enterovirus. ${ }^{2}$ Pregnant women with rubella immunity should be reassured after exposure that reinfection is rare $(<5 \%)$ and the risk of CRS extremely low. ${ }^{2}$ Susceptible pregnant women who have been exposed to rubella should be followed clinically for signs and symptoms of infection, with serologic testing for IgM and IgG every 2 weeks for a 4-week period after the last exposure. Confirmation of rubella in the first trimester warrants consideration of pregnancy termination or, if this is unacceptable, referral to a high-risk obstetrics program.

Prevention: The rubella vaccine currently licensed for use in Canada incorporates liveattenuated virus strain RA27/3, prepared in human diploid cell culture. It is available most often in the trivalent vaccine for measles, mumps and rubella (MMR). Vaccination is very effective and stimulates an antibody response in over $97 \%$ of susceptible individuals. One dose is recommended for chil- 
dren on or just after their first birthday; a second dose of MMR vaccine is administered before school entry, to maximize measles immunity. Women of childbearing age should be given rubella vaccine unless they have proof of immunity, and they should be advised to avoid pregnancy for 3 months after vaccination. Women from countries without good rubella vaccination programs (e.g., the former Soviet Union) may be particularly susceptible to infection. The vaccine is contraindicated in pregnant wo- men and in immunocompromised people, although MMR vaccine is recommended for people with asymptomatic HIV infection. ${ }^{3}$

All suspected cases of rubella should be reported to the local medical officer of health so that urgent public health measures can be taken, especially active case ascertainment, identification and vaccination of susceptible contacts, and reduction of transmission in congregate settings through measures such as exclusion of nonimmunized students from school.
Erica Weir

CMAF

Doug Sider

Associate Medical Officer of Health

Regional Niagara Public Health

Department

Thorold, Ont.

\section{References}

1. Elimination of rubella and congenital rubella syndrome - United States, 1969-2004. MMWR Morb Mortal Wkly Rep 2005;54:279-82.

2. Banatvala J, Brown D. Rubella. Lancet 2004;363:1127-37.

3. Vaccine preventable diseases - rubella. $\mathrm{Ot}$ tawa: Immunization and Respiratory Infections Division, Public Health Agency; 2002. Available: www.phac-aspc.gc.ca /dird-dimr/vpd-mev/rubella_e.html (accessed 2005 May 17).

\section{Adrancing Leadership in Physician Health}

23-24 Seplember 2005

Hilbn Toronb, Toronto, Ont.

PROFESSIONAL DEYELOPMENT PROGRAM

Developed by expert foculty: Dre. Mant Goubs, Micheel Koufrenn. Poul Fornen, Michael Myers and Derek Puddewter.

Giving physician leadiers the skills, hos and resources of promate and protect their own health and that of their physician colleagues.

Phyeitiars with an interst in ar a mandate to, promots the wallnes of calleg gus will derelop an unders tanding of the rikk factors and sporial nosts of physiciars, lsam bo noognits risk situztions and respond effertikely undestand how to create and me intain an enerironment that promotes the wall-being of their colleague, and derrebp peroonal health skilk that allow them to thriks in theircenerand areats balanes in their lifs.
Adsencing Leaderchip in Physiatin Health an ato be brought to you zan irrhouse pognmend deignod spoifically for yourorganization.

\section{Register now!}

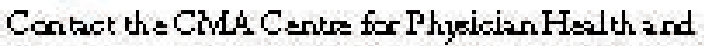
Well-being at $800663-7335 \times 2877$ or $613731-8610$ 2877 suen.yurgblu borme $\alpha$ wikit the centre lookt co crea.ce.

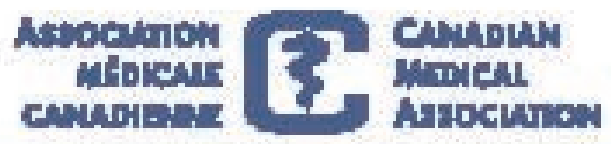

